\title{
Salivary Gland Choristoma of the Middle Ear and Review of the Literature
}

\author{
Serafín Sánchez Gómez, Juan Manuel Maza Solano, José Ramón Armas Padrón, \\ Francisco Refolio Sánchez, Tomás Francisco Herrero Salado \\ Virgen Macarena University Hospital, Seville, Spain \\ Email: sanchezsg@us.es
}

Received April 19, 2013; revised May 15, 2013; accepted June 7, 2013

Copyright (C) 2013 Serafín Sánchez Gómez et al. This is an open access article distributed under the Creative Commons Attribution License, which permits unrestricted use, distribution, and reproduction in any medium, provided the original work is properly cited.

\begin{abstract}
Conductive hearing loss due to middle ear masses is uncommon and usually diagnosed after biopsy. We present a case of a permanent facial palsy occurred following an uneventful biopsy during an exploratory tympanotomy in a salivary gland choristoma of the middle ear. Most salivary gland choristomas have been found in the head and neck. Its location in the ear is extremely rare, and thus we present the 38th case in English and non-English literature from the first publication by Taylor in 1961. Complete surgical removal of salivary gland choristomas of the middle ear is indicated when may not result in permanent damage to the facial nerve. Only biopsy and observation are recommended when the mass is intimately associated with the facial nerve or there are unsafe facial nerve abnormalities. Although the facial nerve is involved in $40 \%$ of cases, transient or even permanent facial palsies are exceptional. The reactivation of latent herpes virus in the facial canal may be involved in facial palsy' etiology following minimal and uneventful middle ear surgery like a biopsy rather than nerve injury related to facial canal malformations.
\end{abstract}

Keywords: Salivary Gland; Choristoma; Middle Ear; Facial Palsy; Herpesvirus Reactivation

\section{Introduction}

Choristomas are not tumors but normal mature tissue masses of a single histological type that are at an abnormal anatomical location [1].

We present a rare condition, the 38th case of salivary gland choristomas of the middle ear in literature from the first publication in 1961 [2-22]. Only one case was bilateral, and described postmortem [23] (see Table 1). Our case was diagnosed by biopsy following an exploratory tympanotomy due to unilateral conductive hearing loss and showed the third reported permanent facial palsy. This article may contribute to the limited clinical knowledge of this condition and assist clinicians in its diagnosis and management.

\section{Case Report}

A 32-years-old Caucasian woman was referred to the ENT Department complaining of hearing loss increased after a delivery and coincident with left ear's acute otitis media (AOM) 3 months before. History of a self-limited ipsilateral facial paresis diagnosed as Bell's palsy 13 months before and a treatment with rifampicin, myam- butol and isoniazid for 6 months treating lymph node tuberculosis 1.5 years before. Otomicroscopy was normal. Pure tone audiometry demonstrated a left ear conductive hearing loss with $40 \mathrm{~dB}$ pantonal air thresholds and normal bone thresholds in low frequencies shifting to $30 \mathrm{~dB}$ for frequencies above $2000 \mathrm{~Hz}$. Tympanogram showed a reduction of compliance, pressures centered at $0 \mathrm{daPa}$ and on-off stapedial reflexes, designating a decreased mobility of the ossicular chain. Preoperative assessment, examination and tests were normal. Exploratory tympanotomy of the left ear was performed under local anesthesia and sedation. Surgical findings included normal tympanic membrane and stringy mucus in the tympanic cavity, occupied by a large polyp-like lesion involving the mesotympanum and the incudo-stapedial joint. Ossicular chain was complete and mobile. We only performed a biopsy of the polypoid mass for diagnostic purposes and a transtympanic drainage was placed. The sample collected was reported as a salivary gland choristoma (Figures 1-3). Inmunohistochemical staining for S-100 protein disclosed the presence of nerve fibers.

An immediate Computed Tomography (CT) scan was performed, showing only a mild hypertrophic middle ear 
Table 1. Salivary gland choristomas of the middle ear reported in the literature $(n=$ number of patients).

\begin{tabular}{|c|c|}
\hline \multirow{2}{*}{ Race } & Caucasian people $97.4 \%(n=37)$ \\
\hline & N/A $2.6 \%(n=1)$ \\
\hline Gender & Women $1.6: 1($ female $\mathrm{n}=23 ;$ male $\mathrm{n}=14 ; \mathrm{N} / \mathrm{A} \mathrm{n}=1)$ \\
\hline \multirow{2}{*}{ Side } & Left ear 1.6:1 (left $\mathrm{n}=23$; right $\mathrm{n}=14)$ \\
\hline & Bilateral $\mathrm{n}=1$ (postmortem) \\
\hline \multirow{4}{*}{ Presentation } & Unilateral hearing loss $>1$ year $87.2 \%(n=33)$ \\
\hline & Neonatal screening $5.3 \%(n=2)$ \\
\hline & School screening $7.9 \%(n=3)$ \\
\hline & Tinnitus $10.5 \%(\mathrm{n}=4)$ \\
\hline \multirow{3}{*}{ Type of hearing loss } & Conductive type $55.3 \%$, moderate in $74 \%$, before age $25(n=21)$ \\
\hline & Sensorineural type $2.6 \%(n=1)$ \\
\hline & N/A $15.8 \%(n=6)$ \\
\hline $\begin{array}{l}\text { Otoscopic visualization of a mass in the } \\
\text { tympanic cavity }\end{array}$ & $37 \%(\mathrm{n}=14)$ \\
\hline \multirow[t]{2}{*}{ Causes of misdiagnosis } & $\begin{array}{l}\text { Seromucous otitis and repetitive AOM } 24 \%(n=9) \text {, undergoing myringotomy and ventilation tube } \\
\text { placement in half of this cases }(n=5)\end{array}$ \\
\hline & Suspicious of fixation of the ossicular chain $15.8 \%(n=6)$ : normal otoscopy, conductive hearing loss \\
\hline \multirow{3}{*}{ Bone malformations } & Affecting portions of the incus and the stapes $60.5 \%(n=23), 50 \%$ simultaneous $(n=19)$ \\
\hline & Malleus $10.5 \%(n=4)$ \\
\hline & Oval and round windows $15.8 \%(n=6)$ \\
\hline \multirow{2}{*}{ Facial nerve abnormalities } & Dehiscent $31.6 \%(n=12)$ \\
\hline & Altered position $7.9 \%(n=3)$ \\
\hline \multirow{3}{*}{ Salivary gland choristomas location } & Posterior region of the tympanic cavity, involving the incudo-stapedial joint $63.2 \%(n=24)$ \\
\hline & $\begin{array}{l}\text { The mass was separated from the medial wall of the tympanic cavity and adjacent to the tympanic } \\
\text { membrane } 5.3 \%(n=2)\end{array}$ \\
\hline & Pedicles have been observed $10.5 \%(n=4)$ \\
\hline \multirow{4}{*}{ Treatment } & Transcanal tympanotomy $76.3 \%(n=29)$ \\
\hline & Retroaural tympanotomy $5.3 \%(\mathrm{n}=2)$ \\
\hline & Mastoidectomy $15.8 \%(n=6)$ \\
\hline & Ossicular chain reconstruction surgery $18.4 \%(n=7)$ \\
\hline \multirow{4}{*}{ Outcomes } & Complete removal $57.9 \%(n=22)$ \\
\hline & Incomplete removal $7.7 \%(\mathrm{n}=3)$ \\
\hline & Only biopsy $28.9 \%(n=11)$ \\
\hline & N/A $7.9 \%(n=3)$ \\
\hline
\end{tabular}

mucosa without destruction of bone structures (Figure 4).

Left facial paresis appeared one day following surgery, grade II according to the House-Brackman scale. Electroneuronography test (ENog) was performed at day $5^{\text {th }}$ showing $36.9 \%$ on the affected side compared to the healthy side, consistent with neuropraxia, so we decided corticosteroid therapy and rehabilitation [24]. IgG antibodies against HSV-1 were not high. Grade II facial pa- resis persisted despite medical treatment, home exercises and electrotherapy, withdrawn a few days later due to earache and hypogeusia. Six months following surgery the patient was admitted for immediate delivery after 31 weeks of gestation and a cesarean section was carried out. The pregnancy was unknown at the time of surgery. Fifteen months following surgery the patient was admitted to the Emergency Room with high fever and low level of consciousness with pustular skin blistering "in starry 


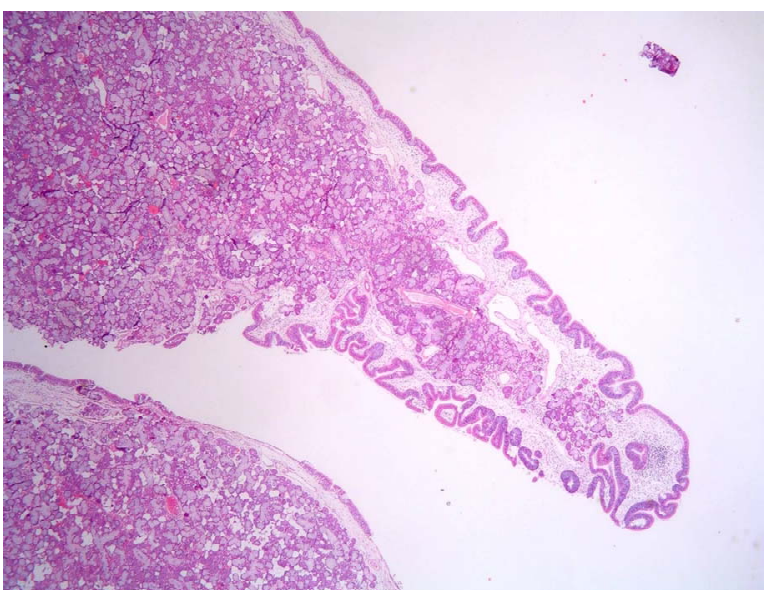

Figure 1. Overview showing polypoid appearance of the lesion. (HE, × 20).

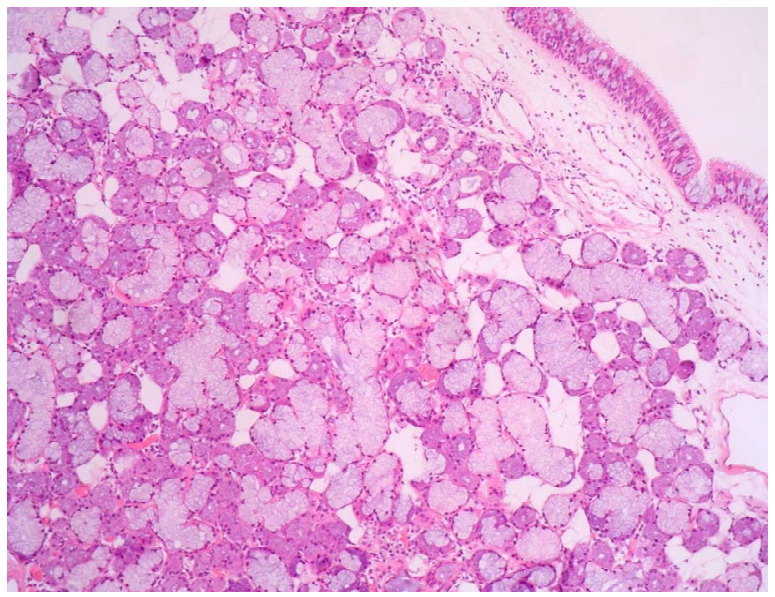

Figure 2. The lesion is covered by a pseudostratified ciliated epithelium with goblet cells and consisting of mucous acini, serous and mixed. (HE, $\times 100)$.

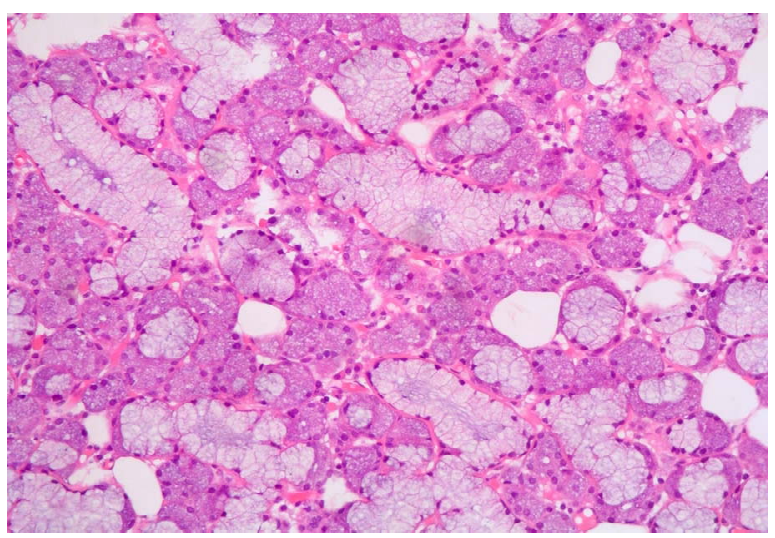

Figure 3. Detail of mucous acini, serous and mixed. (HE, $\times 200)$.

sky" around the upper body consistent with chickenpox. Lab tests of immune status were normal: complete blood cell count, C-reactive protein (CRP), immunoglobulins

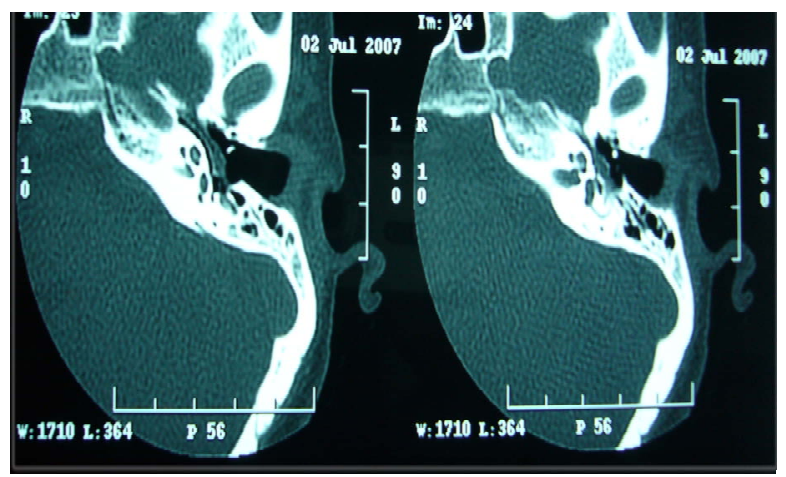

Figure 4. Left-sided temporal bone scan reveals soft tissue density in the middle ear emerging over the promontory. There are no osseous erosions.

(Ig) G, M, and A, antinuclear antibody, and total protein. Blood and CSF culture and serum PCR for herpes-simplex virus were negative. With the diagnosis of chickenpox encephalitis treatment with acyclovir was prescribed [25]. CT scans performed 3 and 4 years after surgery didn't show any increase in the middle ear hypertrophic mucosa or destruction of structures. A Grade I-II facial palsy was the permanent sequela.

\section{Discussion}

Choristomas are also known as heterotopic tissue, ectopia, congenital heterotopic remnants or aberrant debris. Most salivary gland choristomas have been found in head and neck. The most common locations are the paraparotid area, the upper neck, mandible, external ear canal, vulva, mediastinum, cerebellopontine angle, thyroid gland, pituitary gland, rectum, thyroglossal duct, parathyroid capsule, tongue, tonsil, and tonsillar fossa. Most of choristomas are non-neoplastic lesions that do not require excision, unless recent growth is observed in adults or disproportionate growth occurs in childhood, but biopsy is needed for diagnosis [26]. We updated the review conducted by Rinaldo [27] and recent reports [28-37] of middle ear location.

Salivary gland choristomas are the most common type of heterotopic tissue found in the middle ear. Pathogenesis of salivary gland choristomas of the middle ear remains unknown. Willis [38] has suggested 3 possibilities: 1) abnormal persistence and development of vestigial structures; 2) dislocation of a portion of a definitive organ rudiment during mass movement; and 3) heteroplasia, which is abnormal differentiation of local tissues. Abadir [39] suggested that the persistence of remnants of salivary glands in the middle ear must occur before the fourth month of embrionary development. We agree with Nassar [40] that the criteria described by Buckmiller [41] for the definition of a syndrome are present in less than a third part of the reported cases and this condition would not 
constitute a syndrome. Incidental lesions are not consistent enough to describe a syndrome: preauricular fistulae/ cysts, branchial cysts, absence of malleus/stapes muscles, oval and round windows and ossicular anomalies, periauricular alopecia, hemifacial atrophy, situs inversus. Most injuries associated to middle ear salivary gland choristomas are probably due to the sole presence and action of the choristomatous mass and not resulting from abnormal development of the first and second branchial arches. Most ossicular defects described resemble lytic lesions found in other chronic middle ear conditions.

Low otoscopic visualization of a mass in the tympanic cavity (37\%) and high prevalence of conductive hearing loss in patients' first decades of life misdiagnoses the condition. Antecedents of female, hearing loss presentation following a delivery and a Type As Tympanogram directed us to the preoperative diagnosis of ossicular chain fixation.

CT images started to be used in cases published after 1992 and only in 12 patients, when hearing loss was combined with a remarkable image of otoscopic tympanic mass and cases of normal otoscopy and striking high audiometric thresholds. The appearance of the lesions has been described in several colors (yellowish, reddish, brownish or pinkish) and consistency (soft and elastic or rubbery), with smooth or lobulated surfaces. Sizes vary from $2 \mathrm{~mm}$ up to occupy almost the whole tympanic cavity. At any case its length has exceeded the limits of the tympanic cavity, the entrance of the tympanic orifice of the Eustachian tube, the facial recess and the tympanic sinus.

A relatively straightforward differential diagnosis can be formulated with epidermal lesions like granuloma (nodular inflammatory lesion) or cholesteatoma (accumulation of keratin debris within a sac of squamous epithelium in absence of otorrhea), paragangliomas or vascular lesions (vascularized appearance, pulsatile). But the look, feel, location and CT images make the differential diagnosis more challenging with benign or malignant tumors (adenoma, schwannoma, endolymphatic sac tumor, rhabdomyosarcoma, metastatic disease, histiocytosis X). Only histopathological investigations can establish the definite diagnosis of salivary gland choristoma, differentiating it from hamartoma (various mature tissue normally found in the site of lesion), dermoid cysts (ectodermal tissue only with epidermal adnexae), epidermoid cysts (ectodermal tissue with no epidermal adnexae) and teratomas (benign/ malign mature/immature tissues of several embryological origin) [1].

One objective criterion to indicate removal of the lesion when diagnosed is the treatment of conductive hearing loss and avoids the probable course of the hypoacusia to an increase in bone thresholds. Complete surgical removal is indicated when may not result in permanent damage to the facial nerve. Only biopsy and observation are recommended when the mass is intimately associated with the facial nerve or there are unsafe facial nerve abnormalities. Facial nerve electrical monitoring and the use of KTP laser have allowed choristomas removal without neurological sequelae. Involvement of facial nerve or round/oval windows prevents a proper reconstruction of the frequently affected ossicular hearing mechanism (71\%). Incomplete removal of salivary gland choristoma of the middle ear have not ever evolved to malignization, while monitoring of all reported cases has not been long enough to predict a possible malignancy. Rinaldo [27] points to a prominent benign behavior of ear's salivary gland choristomas in her literature review, including 4 malignant salivary gland tumors originating from the middle ear and speculatively evolving from choristomas.

Despite the frequent involvement of the facial nerve (40\%), only two transient facial palsies and three permanent ones (10.5\% of patients) have been described following surgery. Surgical damage may appear as the immediate cause of the facial paresis/palsy, but herpesvirus implication could be considered even with lower HSV-1 titers: our patient had suffered a previous transient episode of facial palsy and subsequently presented a rare herpetic encephalitis ( 1.7 cases of encephalitis per 100,000 cases of chickenpox). Clinical practice guidelines recommend treatment with acyclovir even in undiagnosed herpetic encephalitis but suspected. Unknown host immune factors and the unsuspected pregnancy may be responsible to suffer facial palsy even before 2.5 days described in Bonkowsky series [42]. This supports the hypothesis of facial palsy by reactivation of latent herpes viral particles stationed in the geniculate ganglion when surgery is limited to a non-damaging simple biopsy [43].

\section{Conclusion}

Complete surgical removal or rare salivary gland choristomas of the middle ear is indicated when may not result in permanent damage to the facial nerve. Only biopsy and observation are recommended when the mass is intimately associated with the facial nerve or there are unsafe facial nerve abnormalities. Although facial nerve is involved in $40 \%$ of middle ear's choristomas, transient or even permanent facial palsies are exceptional. The reactivation of latent herpes virus in the facial canal may be involved in facial palsy's etiology following minima land uneventful middle ear surgery like a biopsy rather than nerve injury related to facial canal malformations.

\section{REFERENCES}

[1] A. Ferlito and K. O. Devaney, "Developmental Lesions of the Head and Neck. Terminololgy and Bio-Logical Behavior," The Annals of Otology, Rhinology, and Laryn- 
gology, Vol. 104, 1995, pp. 913-918.

[2] G. D. Taylor and H. F. Martin, "Salivary Gland Tissue in the Middle Ear: A Rare Tumor," Archives of Otolaryngology, Vol. 73, 1961, pp. 651-653.

http://dx.doi.org/10.1001/archotol.1961.00740020665006

[3] N. Morimoto, K. Ogawa and J. Kanzaki, "Salivary Gland Choristoma in the Middle Ear: A Case Report," American Journal of Otolaryngology, Vol. 20, No. 4, 1999, pp. 232235. http://dx.doi.org/10.1016/S0196-0709(99)90005-4

[4] B. P. Perry, R. L. Scher, L. Gray, E. H. Bossen and D. L. Tucci, "Pathologic Quiz Case 1. Salivary Gland Choristoma of the Middle Ear," Archives of OtolaryngologyHead and Neck Surgery, Vol. 124, No. 6, 1998, pp. 714716.

[5] W. Anderhuber, A. Beham, C. Walch and H. Stammberger, "Choristoma of the Middle Ear," European Archives of Oto-Rhino-Laryngology, Vol. 253, No. 3, 1996, pp. 182-184. http://dx.doi.org/10.1007/BF00615119

[6] M. L. Hinni and C. W. Beatty, "Salivary Gland Choristoma of the Middle Ear: Report of a Case and Review of the Literature," Ear, Nose \& Throat Journal, Vol. 75, No. 7, 1996, pp. 422-424.

[7] I. Namdar, E. E. Smouha and P. Kane, "Salivary Gland Choristoma of the Middle Ear: Role of Intraoperative Facial Nerve Monitoring," Otolaryngology-Head and Neck Surgery, Vol. 112, No. 4, 1995, pp. 616-620.

[8] H. Münster, "Salivary Gland Choristoma in the Middle Ear," Ugeskr Laeger, Vol. 156, No. 31, 1994, pp. 44744475.

[9] D. L. Cejas Méndez, J. L. de Serdio Arias and S. Goralsky Filonov, "Choristoma of the Salivary Gland and Dermoid Cyst of the Middle Ear in a 3 Year Old Girl. A Propos of a Case," Nales Otorrinolaringologicos Iberoamericanos, Vol. 19, No. 3, 1992, pp. 275-282.

[10] I. D. Bottrill, O. P. Chawla and A. D. Ramsay, "Salivary Gland Choristoma of the Middle Ear," Journal of Laryngology \& Otology, Vol. 106, No. 7, 1992, pp. 630-632. http://dx.doi.org/10.1017/S0022215100120389

[11] P. J. Moore, B. N. Benjamin and A. E. Kan, "Salivary Gland Choristoma of the Middle Ear," International Journal of Pediatric Otorhinolaryngology, Vol. 8, No. 1, 1984, pp. 91-95.

http://dx.doi.org/10.1016/S0165-5876(84)80029-4

[12] J. M. Kartush and M. D. Graham, "Salivary Gland Choristoma of the Middle Ear: A Case Report and Review of the Literature," Laryngoscope, Vol. 94, No. 2, 1984, pp. 228-230.

[13] K. L. Saeger, P. Gruskin and J. N. Carberry, "Salivary Gland Choristoma of the Middle Ear," Archives of Pathology \& Laboratory Medicine, Vol. 106, No. 1, 1982, pp. 39-40.

[14] A. Quaranta, F. Mininni and L. Resta, "Salivary Gland Choristoma of the Middle Ear: a Case Report," Journal of Laryngology \& Otology, Vol. 95, No. 9, 1981, pp. 953956. http://dx.doi.org/10.1017/S0022215100091660

[15] C. R. Cannon, "Salivary Gland Choristoma of the Middle Ear," American Journal of Otolaryngology, Vol. 1, No. 4, 1980, pp. 250-251.
[16] H. A. Kley, "Middle Ear Choristoma," Laryngologie, Rhinologie Otologie, Vol. 58, 1979, pp. 65-67.

[17] R. E. Mischke, D. E. Brackmann and P. Gruskin, "Salivary Gland Choristoma of the Middle Ear," Archives of Otolaryngology, Vol. 103, No. 7, 1977, pp. 432-434. http://dx.doi.org/10.1001/archotol.1977.00780240090016

[18] C. J. Wine and J. E. Metcalf, "Salivary Gland Choristoma of the Middle Ear and Mastoid," Archives of Otolaryngology, Vol. 103, No. 7, 1977, pp. 435-436. http://dx.doi.org/10.1001/archotol.1977.00780240093017

[19] D. Hociotā and T. Ataman, "A Case of Salivary Gland Choristoma of the Middle Ear," Journal of Laryngology \& Otology, Vol. 89, No. 10, 1975, pp. 1065-1068. http://dx.doi.org/10.1017/S0022215100081378

[20] R. C. Bruner, "Salivary Gland Choristoma of the Middle Ear. A Case Report," Archives of Otolaryngology, Vol. 91, No. 3, 1970, p. 303.

http://dx.doi.org/10.1001/archotol.1970.00770040409019

[21] C. B. Caplinger and J. F. Hora, "Middle Ear Choristoma with Absent Oval Window: A Report of One Case," Archives of Otolaryngology, Vol. 85, No. 4, 1967, pp. 365366.

http://dx.doi.org/10.1001/archotol.1967.00760040367004

[22] T. N. Steffen and W. F. House, "Salivary Gland Choristoma of the Middle Ear," Archives of Otolaryngology, Vol. 76, 1962, pp. 74-75.

http://dx.doi.org/10.1001/archotol.1967.00760040367004

[23] G. A. Braun, L. D. Lowry and A. Meyers, "Bilateral Choristomas of the External Auditory Canals," Archives of Otolaryngology, Vol. 104, No. 8, 1978, pp. 467-470. http://dx.doi.org/10.1001/archotol.1978.00790080049013

[24] M. Grosheva, C. Wittekindt and O. Guntinas-Lichius, "Prognostic Value of Electroneurography and Electromyography in Facial Palsy," Laryngoscope, Vol. 118, No. 3, 2008, pp. 394-397. http://dx.doi.org/10.1097/MLG.0b013e31815d8e68

[25] A. R. Tunkel, C. A. Glaser, K. C. Bloch, et al., "The Management of Encephalitis: Clinical Practice Guidelines by the Infectious Diseases Society of America," Clinical Infectious Diseases, Vol. 47, No. 3, 2008, pp. 303-327. http://dx.doi.org/10.1086/589747

[26] R. P. S. Harar, N. J. Eynon-Lewis, F. Scarivilli and G. B. Brookes, "Extensive Salivary Gland Choristoma of the Pterygopalatine Fossa," Otolaryngology-Head and Neck Surgery, Vol. 122, No. 4, 2000, pp. 611-612. http://dx.doi.org/10.1016/S0194-5998(00)70114-8

[27] A. Rinaldo, A. Ferlito and K. O. Devaney, "Salivary Gland Choristoma of the Middle Ear," Journal for OtoRhino-Laryngology and Its Related Specialties, Vol. 66, No. 3, 2004, pp. 141-147. http://dx.doi.org/10.1159/000079334

[28] S. Z. Toros, E. Egeli, Y. Kiliçarslan, G. Gümrükçü, T. Gökçeer and H. Noşeri, "Salivary Gland Choristoma of the Middle Ear in a Child with Situs Inversus Totalis," Auris Nasus Larynx, Vol. 37, No. 3, 2010, pp. 365-368. http://dx.doi.org/10.1016/j.anl.2009.09.003

[29] M. Enoz and Y. Suoglu, "Salivary Gland Choristoma of the Middle Ear," Laryngoscope, Vol. 116, No. 6, 2006, 
pp. 1033-1034.

http://dx.doi.org/10.1097/01.mlg.0000217250.08455.d3

[30] M. S. Boleas-Aguirre, S. Ernst, F. J. Cervera-Paz, A. Panizo and M. Manrique, "Salivary Gland Choristoma (Hamartoma) of the Middle Ear: A Case Report," Revue de Laryngologie Otologie Rhinologie, Vol. 127, No. 4, 2006, pp. 247-249.

[31] D. Yazici and F. Cetik, "An Infrequent Mass of the Middle Ear: Salivary Gland Choristoma," Archives of Otolaryngology-Head and Neck Surgery, Vol. 132, No. 11, 2006, pp. 1260-1262. http://dx.doi.org/10.1001/archotol.132.11.1260

[32] D. K. Lee, J. H. Kim, Y. S. Cho, W. H. Chung and S. H. Hong, "Salivary Gland Choristoma of the Middle Ear in an Infant: a Case Report," International Journal of Pediatric Otorhinolaryngology, Vol. 70, No. 1, 2006, pp. 167170. http://dx.doi.org/10.1016/j.ijporl.2005.05.030

[33] P. Simoni, B. J. Wiatrak and D. R. Kelly, "Choristomatous Polyps of the Aural and Pharyngeal Regions: First Simultaneous Case," International Journal of Pediatric Otorhinolaryngology, Vol. 67, No. 2, 2003, pp. 195-199. http://dx.doi.org/10.1016/S0165-5876(02)00368-3

[34] Y. Ookouchi, N. Honda and K. Gyo, "Salivary Gland Choristoma of the Middle Ear in a Child: A Case Report," Otolaryngology—Head and Neck Surgery, Vol. 128, No. 1, 2003, pp. 160-162. http://dx.doi.org/10.1067/mhn.2003.78

[35] J. P. Vasama, H. Ramsay and A. Markkola, "Choristoma of the Middle Ear," Otology \& Neurotology, Vol. 22, No. 3, 2001, pp. 363-368. http://dx.doi.org/10.1097/00129492-200105000-00033

[36] S. L. Ha, J. E. Shin and T. H. Yoon, "Salivary Gland Choristoma of the Middle Ear: A Case Report," American Journal of Otolaryngology, Vol. 21, No. 2, 2000, pp. 127130. http://dx.doi.org/10.1016/S0196-0709(00)85011-5
[37] P. Supiyaphun, K. Snidvongs and S. Shuangshoti, "Salivary Gland Choristoma of the Middle Ear: Case Treated with KTP Laser," Journal of Laryngology \& Otology, Vol. 114, No. 7, 2000, pp. 528-532. http://dx.doi.org/10.1258/0022215001906066

[38] R. A. Willis, "Some Unusual Developmental Heterotopias," British Medical Journal, Vol. 3, 1968, pp. 267-272. http://dx.doi.org/10.1136/bmj.3.5613.267

[39] W. F. Abadir and W. S. Pease, "Salivary Gland Choristoma of the Middle Ear," Journal of Laryngology \& Otology, Vol. 92, No. 3, 1978, pp. 247-252. http://dx.doi.org/10.1017/S0022215100085297

[40] M. N. Nassar and O. I. Mansour, "Salivary Gland Choristoma of the Middle Ear. A Case Report and Review of the Literature," Mediterranean Journal of Otology, Vol. 3, No. 1, 2007, pp. 47-52.

[41] L. M. Buckmiller, H. A. Brodie, K. J. Doyle and W. Nemzek, "Choristoma of the Middle Ear: A Component of a New Syndrome?" Otology \& Neurotology, Vol. 22, No. 3, 2001, pp. 363-368. http://dx.doi.org/10.1097/00129492-200105000-00015

[42] V. Bonkowsky, B. Kochanowsky, J. Strutz, P. Pere, W. Hosemann and W. Arnold, "Delayed Facial Palsy Following Uneventful Middle Ear Surgery: A Herpes Simplex Virus Type 1 Reactivation?," Annals of Otology, Rhinology, and Laryngology, Vol. 107, No. 11, 1998, pp. 901905.

[43] K. Kawaguchi, H. Inamura, Y. Abe, H. Koshu, E. Takashita, Y. Muraki, et al., "Reactivation of Herpes Simplex Virus Type 1 and Varicella-Zoster Virus and Therapeutic Effects of Combination Therapy with Prednisolone and Valacyclovir in Patients with Bell's Palsy," Laryngoscope, Vol. 117, No. 1, 2007, pp. 147-156. http://dx.doi.org/10.1097/01.mlg.0000248737.65607.9e 